Sir,

\section{Creutzfeldt-Jakob disease presenting with visual disturbance}

Creutzfeldt-Jakob disease (CJD) is a rare progressive neurodegenerative disease which commonly presents with rapid onset of dementia. Death within 1 year occurs in around $90 \%$ of patients. It is a transmissible spongiform encephalopathy and was initially considered to be due to a 'slow virus'. However, the transmissible agent does not demonstrate the characteristic features of a virus, lacking DNA or RNA, and the term 'prion' was adopted to refer to these 'infectious proteins'. ${ }^{1-4}$

Visual disturbance is reported in a third or more of patients during the course of the disease. ${ }^{1,3}$ However, few cases present primarily to the ophthalmologist. A case of CJD is described in which the presenting feature was visual disturbance in conjunction with a field defect. The appropropriate investigations, management and ultimate diagnosis of CJD are discussed.

\section{Case report}

A 57-year-old man, who had retired 5 years previously complaining of 'burn out', presented to the ophthalmic department with visual distortion. He himself had noted a field defect while working on his computer keyboard. Over the next 2-6 weeks he complained that images were becoming fragmented. In particular, pictures appeared to be moving and faces were moving and distorting and separating from their bodies. Colours, in particular green, orange and red, seemed more intense than normal. He also complained of mild frontal headache and occasional nausea.

Corrected visual acuities were recorded as 6/6 in each eye. He had normal anterior segments and intraocular pressures and optic discs and maculae were unremarkable. There was evidence of mild arteriovenous nipping of the vessels, consistent with his hypertension. Visual fields revealed a left incongruous homonymous field defect. A CT scan was reported as normal and fluorescein angiography showed areas of

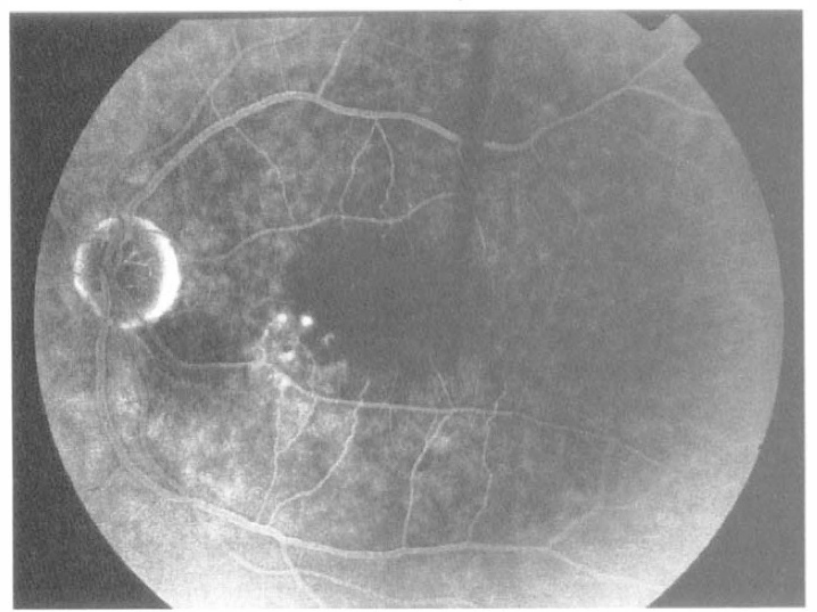

Fig. 1. Fluorescein angiogram of the left eye showing areas of hyperfluorescence in the papillomacular area.

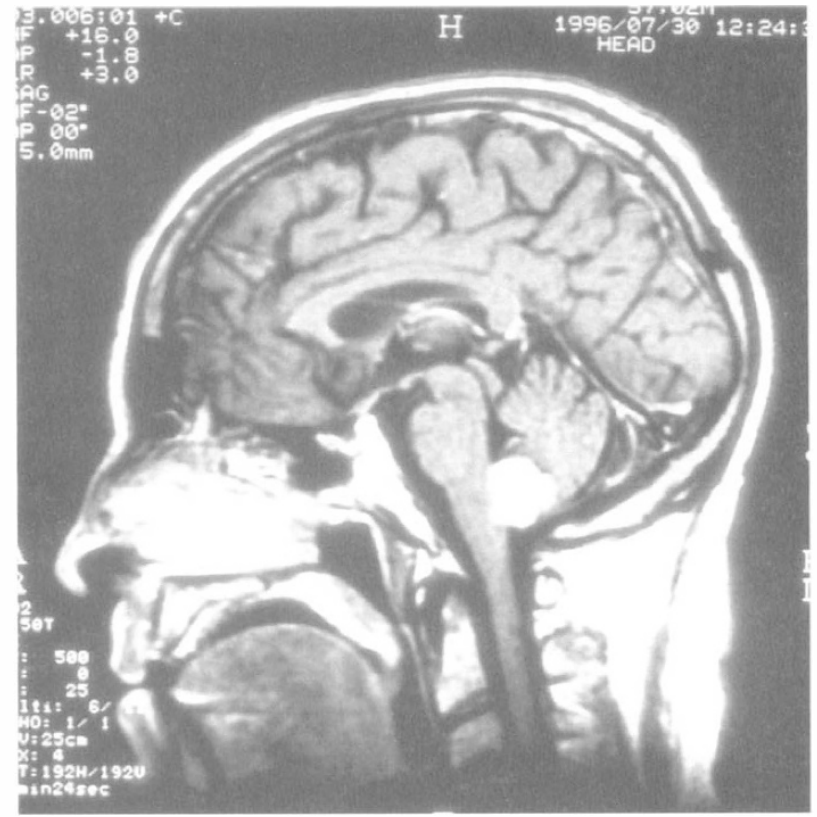

Fig. 2. MRI scan showing a subependymoma of the fourth ventricle.

hyperfluorescence in the papillomacular areas consistent with defects at the level of the retinal pigment epithelium (Fig. 1).

His symptoms became progressively worse and visual acuity dropped to $6 / 36$ in the right eye and 3/60 in the left. He developed an occasional expressive dysphasia and mild short-term memory loss. He had become increasingly sleepy, emotionally labile and unsteady when walking. He was admitted for further neurological investigation and during this time developed marked myoclonus. An MRI scan (Fig. 2) showed a meningioma of the fourth ventricle and an electroencephalogram (EEG) showed bursts of slow activity with posterior spikes with long runs of occipital spikes. Following intravenous diazepam infusion, the discharges were less frequent and visual symptoms improved.

It is likely that the meningioma on MRI scanning was an incidental finding as its site and location would not account for his symptoms. Cerebral angiography failed to detect any vascular abnormality. On the initial EEG findings it was presumed that the patient had occipital

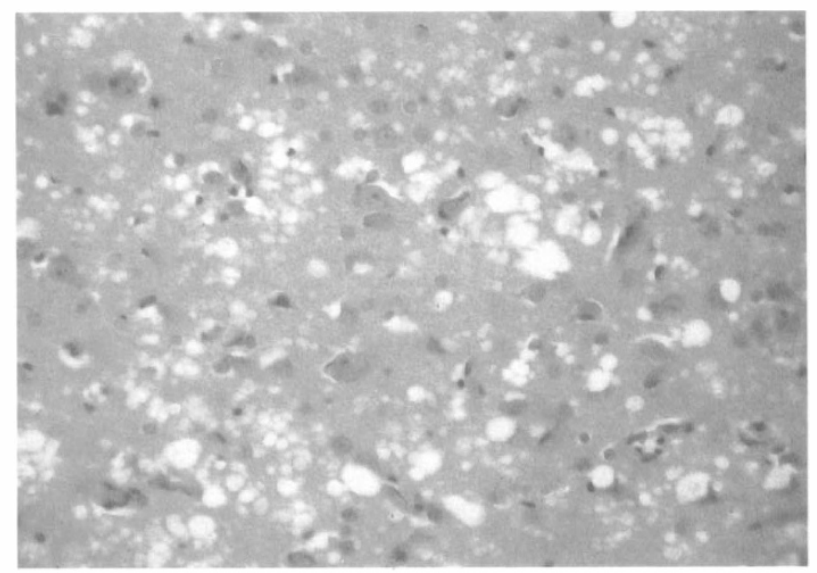

Fig. 3. Section of the cerebral cortex showing spongiform degeneration. 


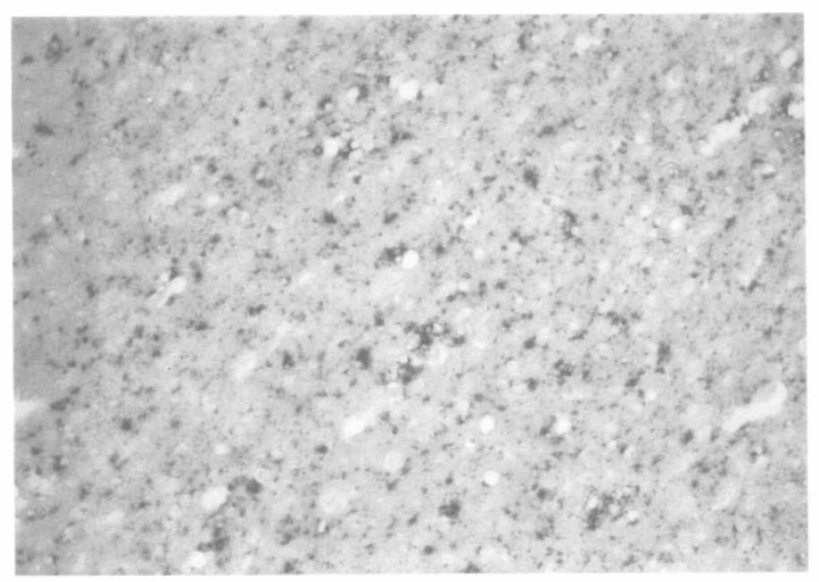

Fig. 4. Positive staining for protein in the cerebral cortex.

lobe epilepsy, but as the myoclonic jerking became more pronounced, repeat EEG showed the classic periodic complexes of CJD.

Vision progressively deteriorated and he became more emotional and disorientated. A brain biopsy was considered, but eventually was not undertaken as the clinical state became more apparent. At this stage, repeat EEG demonstrated typical CJD complexes. Two weeks later the patient died.

A post-mortem examination confirmed the diagnosis of CJD. Sections of the cerebral cortex showed widespread spongiform encephalopathy (Fig. 3), particularly marked in the occipital cortex, with widespread neuronal loss and astrocytic gliosis. Immunocytochemistry for prion protein (Fig. 4) was positive in these regions. A lesser degree of spongiform change was noted in the basal ganglia, thalamus and hypothalamus. A fourth ventricle meningioma was also identified.

\section{Comment}

Bizarre colour perception, generalised or hemianopic visual loss and diplopia may be presenting features of CJD. ${ }^{3}$ Distortion of vision, in particular the dimensions of faces and objects, have also been described ${ }^{5}$ Less frequently, oculomotor disorders may manifest with nystagmus or supranuclear palsies, and rarely with isolated sixth nerve palsy, mydriasis or ptosis. ${ }^{3}$

Metamorphopsia, in which objects appear distorted, may be caused by ocular lesions or focal lesions close to the visual cortex and geniculostriate nucleus. ${ }^{6}$ Palinopsia, whereby visual images persist after the removal of a stimulus, has also been described as a presenting sign of CJD. Palinopsia may be noted as a visual field defect progresses and may be associated with other defects in visual perception such as the distortion of size or shape of objects and the illusion of motion. ${ }^{7}$

Visual hallucinations, in which a person claims to see something that the observer cannot see, has also been reported with CJD. ${ }^{8}$ Hallucinations can be produced by a variety of neurological, toxic, metabolic and psychiatric disorders as well as ophthalmological disease and can occur with a variety of conditions. ${ }^{9}$
In the presented case a left homonymous field defect was documented on presentation, and the patient had symptoms of visual distortion of size and shape with abnormal colour perception, which are reported findings in CJD. In particular, hemifield disturbance is often reported $^{10,11}$ and has also been seen in the context of CJD associated with dura mater graft, $^{12}$ as well as occurring in the ataxic form. ${ }^{13}$ Ophthalmic examination at presentation was unremarkable; however, fluorescein angiography did show localised areas of retinal pigment epithelial defects at both maculae. The significance of this is uncertain, but is unlikely to account for the symptoms.

Palinopsia (or visual perseveration) occurs when a patient continues to perceive an image after the original stimulus has been removed, and may occupy all or part of the visual field. Palinopsic episodes are not fully understood, but have been shown to respond to anticonvulsants and may represent a type of sensory seizure. ${ }^{7}$ Our patient reported improvement in visual symptoms following infusion of diazepam. Prolongation of a visual image may be specific to a certain stimulus for instance, colour, shape or duration - possibly due to loss of inhibition of visual memory pathways. ${ }^{7}$ In our case the patient complained that colours, especially green, orange and red, were particularly intense, which could be due to perseveration of these specific stimuli. In general, palinopsia is associated with focal lesions in the parieto-occipital area of the non-dominant hemisphere ${ }^{7}$ and can be caused by a variety of conditions.

Previous studies have attempted to subdivide CJD to include one group in which visual symptoms predominate, referred to as 'Heidenhain syndrome' ${ }^{14}$ Others have similarly subdivided cases of CJD, referring to certain cases showing diffuse change particularly in the parieto-occipital area of the brain. ${ }^{15}$

Our patient had features of metamorphopsia and, later, palinopsia, and interestingly was shown to have extensive occipital lobe involvement at post-mortem. Similar to the case reported by Purvin et al. ${ }^{7}$ our patient had (with the exception of the incidental meningioma) no focal signs demonstrable on neuroimaging or cerebral angiography, yet demonstrated focal clinical signs.

Diagnosis of CJD has to be made clinically on the presence of dementia, myoclonus and periodic EEG activity (usually triphasic 1 cycle/second) ${ }^{3}$ and neuropathologically on the detection of prion protein and the presence of spongiform encephalopathy. ${ }^{16}$

The incidence of sporadic cases of CJD in the United Kingdom has increased, particularly among the older age groups, probably due to more accurate diagnosis than an actual increase in incidence. In recent years a group of young patients with CJD (mainly under 40 years) and a high incidence of CJD in dairy farmers has been identified. ${ }^{16}$ The new variant of CJD has similar clinical features to other forms, but psychiatric symptoms, in particular depression, and sensory disturbances such as paraesthesiae appear to be an early feature of variant disease. $^{8,17,18}$ 
'Prion disease ${ }^{2}$ refers to progressive, subacute, degenerative disease of the CNS, and in addition to CJD includes Gerstmann-Straussler-Scheinker disease (GSS), kuru, fatal familial insomnia and familial atypical dementia. Similar diseases which occur in animals include scrapie in sheep and bovine spongiform encephalopathy (BSE) in cattle. What prion diseases have in common is an abnormal protease-resistant isoform of the prion protein $(\mathrm{PrP})$ which is normally expressed by neurons. Genetic analysis of the PrP gene can help to differentiate familial and sporadic disease. In addition, the homozygous methionine genotype at codon 129 of the PrP gene occurs in all cases of variant CJD but only $70 \%$ of sporadic cases, and further work is being undertaken to look at the susceptibility to variant CJD in individuals who are heterozygous or valine homozygous at codon 129. However, to date definitive diagnosis of CJD can only be made histologically. PrP glycotyping on western blot may help to differentiate variant and sporadic disease. $2,17,18$

With improved awareness of CJD and its clinical manifestations, ophthalmic signs may prove a useful aid in the early diagnosis of this condition.

\section{References}

1. Will RG, Matthews WB. A retrospective study of Creutzfeldt-Jakob disease in England and Wales 1970-79. I. Clinical features. J Neurol Neurosurg Psychiatry 1984;47:134-40.

2. Bruton CJ, Bruton RK, Gentleman SM, Roberts GW. Diagnosis and incidence of prion (Creutzfeldt-Jakob) disease: a retrospective archival survey with implications for future research. Neurodegeneration 1995;4:357-68.

3. Brown P, Cathala F, Castaigne P, Gajdusek DC. Creutzfeldt-Jakob disease: clinical analysis of a consecutive series of 230 neuropathologically verified cases. Ann Neurol 1986;20:597-602.

4. Goldhammer Y. Creutzfeldt-Jakob disease and the ophthalmologist. J Clin Neuro-ophthalmol 1989;9:247-8.

5. Young GR, Fletcher NA, Zeidler M, Estibeiro KL, Ironside JW. Creutzfeldt-Jakob disease in a beef farmer. Lancet 1996;348:610-1.

6. Critchley M. Metamorphopsia of central origin. Trans Ophthalmol Soc UK 1949;69:111-21.

7. Purvin V, Bonnin J, Goodman J. Palinopsia as a presenting manifestation of Creutzfeldt-Jakob disease. J Clin Neuroophthalmol 1989;9:242-6.

8. Zeidler M, Johnstone EC, Bamber RWK, Dickens CM, Fisher $\mathrm{CJ}$, et al. New variant Creutzfeldt-Jakob disease: psychiatric features. Lancet 1997;350:908-10.

9. Cummings JL, Miller BL. Visual hallucinations: clinical occurrence and use in differential diagnosis. West J Med 1987;146:46-51.

10. Staffen W, Trinka E, Iglseder B, Pilz P, Homann N, et al. Clinical and diagnostic findings in a patient with Creutzfeldt-Jakob disease (type Heidenhain). J Neuroimag 1997;7:50-4.

11. Vargas ME, Kupersmith MJ, Savino PJ, Petito F, Frohman LP, et al. Homonymous field defect as the first manifestation of Creutzfeldt-Jakob disease. Am J Ophthalmol 1995;119:497-504.

12. Masullo C, Pocchiari M, Macchi G, Alema G, Piazza G. Transmission of Creutzfeldt-Jakob disease by dural cadaveric graft. J Neurosurg 1989;71:954-5.
13. Jellinger K, Heiss WD, Deisenhammer E. The ataxic (cerebellar) form of Creutzfeldt-Jakob disease. J Neurol 1974;207:289-305.

14. Meyer A, Leigh D, Bagg CT. A rare presenile dementia associated with cortical blindness (Heidenhain's syndrome). J Neurol Neurosurg Psychiatry 1954;17:129-33.

15. Nevin S. On some aspects of cerebral degeneration in later life. Proc R Soc Med 1967;60:517-26.

16. Cousens SN, Zeidler M, Esmonde TF, De Silva R, Wilesmith JW, et al. Sporadic Creutzfeldt-Jakob disease in the United Kingdom: analysis of epidemiological surveillance data for 1970-96. BMJ 1997;315:389-95.

17. Pocchiari M. Early identification of variant Creutzfeldt-Jakob disease. BMJ 1998;316:563-4.

18. Zeidler M, Stewart GE, Barraclough CR, Bateman DE, Bates $D$, et al. New variant Creutzfeldt-Jakob disease: neurological features and diagnostic tests. Lancet 1997;350:903-7.

\section{A.M. McElvanney}

Eye Department

Royal Surrey County Hospital

Guildford

Surrey GU2 5XX, UK

M. G. Boodhoo

Eye Department

Saint Peter's Hospital

Chertsey

Surrey KT16 OPZ, UK

Miss A.M. McElvanney

Eye Department

St George's Hospital

Blackshaw Road

London SW17 0QT, UK

Sir,

Indocyanine green angiographic imaging of central retinal artery occlusion with cilioretinal sparing Central retinal artery occlusion (CRAO) is an ophthalmic emergency that generally results in a poor prognosis. Vision is severely affected unless a cilioretinal artery is present to supply circulation to the macular area. Although fundus fluorescein angiography (FFA) clearly demonstrates retinal vascular defects associated with CRAO, indocyanine green (ICG) angiographic features of this clinical entity are not well documented. Here we describe the ICG angiographic images and the choroidal and retinal alterations in a case of CRAO with cilioretinal sparing.

\section{Case report}

A 66-year-old woman with a 5-year history of hypertension reported the sudden onset of painless decreased vision in the right eye, which had started $12 \mathrm{~h}$ earlier. On examination her best corrected visual acuity was counting fingers with her right eye and 20/20 in the left eye. A right, relative afferent pupillary defect was present. Anterior segment examinations were normal and intraocular pressure (IOP) was $14 \mathrm{mmHg}$ in both eyes. Fundus examination of the right eye showed segmentation of the blood column in the retinal arteries and diffuse whitening of the retina, except for the localised area between the fovea and the optic disc, indicating CRAO with cilioretinal sparing. Examination 